\title{
Membership and Fees 1997 Admission et cotisation
}

Membership in either the Canadian Political Science Association and/or the Société québécoise de science politique includes a subscription to the Canadian Journal of Political Science. Joint membership or Société-only membership also includes a subscription to la Sociétés journal Politique et Sociétés.

There are two levels of membership fees. Income level stated refers to gross annual income (before taxes). Members may subscribe to Canadian Public Policy at a special rate.

La cotisation versée à l'Association canadienne de science politique et/ou à la Société québécoise de science politique donne droit à un abonnement à la Revue canadienne de science politique. L'adhésion aux deux organismes ou à la Société seulement donne également droit à un abonnement à la revue de la Société, Politique et Sociétés.

Il y a deux niveaux de cotisation dans chaque catégorie. La cotisation est fonction de votre revenu annuel brut (avant impôt). En tant que membre il vous est possible de vous abonner à un tarif avantageux à Analyse des politiques.

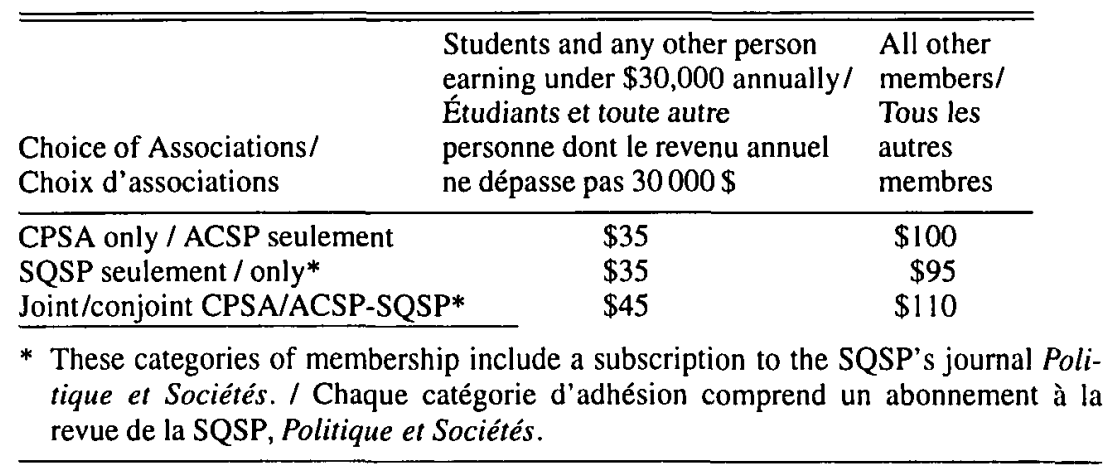

\footnotetext{
Institutional subscription - $\$ 65$ (+ 7\% GST 11883 5289RT) in Canada;

$\$ 85$ in member countries of OECD;

$\$ 65$ in all other countries

Abonnement institutionnel $-65 \$(+7 \%$ TSP 11883 5289RT) au Canada;

$85 \$$ dans les pays membres de l'OCDE;

$65 \$$ dans tout autre pays
}

For information, please write: /

Pour de plus amples renseignements, veuillez vous adresser à :

Canadian Journal of Political Science /

Revue canadienne de science politique

\#205-1, rue Stewart Street

Ottawa, Ontario K1N 6H7 